\title{
SARCOSPORIDIOSIS AS A NEGLECTED DISEASE BETWEEN CARCASSES AND SLAUGHTER HOUSE WORKERS
}

By

SHIMAA ABDEL-RADI ${ }^{1}$ AND NANCY O. KAMEL ${ }^{2}$

Department of Parasitology, Faculty Veterinary Medicine, Cairo University, Giza, and Department of Parasitology, Faculty of Medicine, October 6 University, Giza, Postal code: 12585, Egypt

\section{Abstract}

This studied the medical complains in group of slaughter house workers in daily contact to slaughtered buffaloes. Carcasses of 400 slaughtered buffaloes were examined for Sarcocystis muscle cyst infection. Bradyzoites extracted from the diagnosed Sarcocystis muscle cyst (SMC) were used for production of Sarcocystis bradyzoites antigens (SBAg). The antigen was fractionated. Eluted concentrated specific fractions of 35-63 Kda molecular weight (MW) after EITB were used for infection sero-diagnosis of slaughtered buffaloes and Slaughter house workers using Dot ELISA. Data revealed that infection in slaughtered buffaloes was $36.57 \%$ by macro and microscopic investigation. Anti-Sarcocystis anti-bodies (ASAb) by dot ELISA were $52.5 \%$ among buffaloes. Sensitivity was $100 \%$, specificity was $86.66 \%$ with $93.33 \%$ validity.

Using the previous technique in examination of group of slaughter house workers revealed high association between presence of ASAb in sera of patients complained from Myositis and arthritis (66.0\%) followed by those complained by Myositis (50\%) only, while it was $44.0 \%$ in workers complained by arthritis only. No ASAb was recorded in $4^{\text {th }}$ group complained by digestive disturbances only as well as in control healthy individuals.

Key words: Sarcocystis spp., Buffaloes, Slaughter house workers, EITB, Dot-ELISA.

\section{Introduction}

The members of the genus Sarcocystis (Apicomplexa: Sarcocystidae) are intracellular protozoan parasites that infect a wide range of domestic and wild animals, birds as well as man, resulting in economic losses in production animals worldwide (Saeed et al, 2018). In Egypt infection was reported in aquatic birds (El-Morsey et al, 2014), water buffaloes (Ashmawy et al, 2014) and man as final and intermediate host for sarcosporidiosis (Shaapan, 2016). Its sexual stages are in the intestine of a carnivore (final host) while the asexual stages are in the vascular system and musculature of the animals and man as intermediate host (Fayer et al, 2015) causing weight loss, anorexia, anemia, abortion, debilitation and mortality (Badawy et $a l, 2012)$. Besides, man may serve as intermediate or definitive hosts for S. bovihominis and S. suihominis by eating raw or inadequately infected cooked beef infected (Cook and Zumla, 2003). This caused intestinal and muscular sarcocystosis in man, persistent myalgia and/or myositis and episodic weakness (Bunyaratvej et al, 2007).
No pre-slaughtering test was adopted for diagnosis of sarcocystosis in muscles of living animals, but the clinical pictures of SMC in human were nonspecific and confused with many other diseases, (Cocuz, 2014). ELISA proved an easily applicable test suitable for evaluating large number of samples simultaneously depending on antigen degree of purity and specificity (Hewitson et al, 2009; Taher, 2012). Dot ELISA by using very minute amount of sera and antigen easily was read visually and ability of extracting specific protein fraction after EITB, Dot ELISA proved as an accurate test gather the benefits of ELISA and that of EITB (ElBahy, 2002).

The present work investigated the distributions of sarcocspordiosis in slaughtered buffaloes as a causative agent for some medical complains recorded in some slaughter house workers using Dot ELISA through the following steps: 1- Investigation the level of infection in slaughtered buffaloes aiming to determine the problem level among these workers and collection of known infected sera. 2- Preparation and fractionation of 
SBAg using SDS-PAGE to determine specific KDa protein fractions that eluted and concentrated to be used as specific parasite Ag in Dot ELISA. 3- Determination of presence of ASAb in sera of slaughter house workers using modified Dot ELISA after its standardization from the aspect of sensitivity and specificity.

\section{Material and Methods}

Ethical approval: All study steps and procedures were approved by the Institutional Animal Care and Use ethical Committee (CU-IACUC), Cairo University. The study was carried out during the period from April to October 2018 in the laboratory of Parasitology, Faculty of Veterinary Medicine, Cairo University.

Collection and examination of buffaloes' samples: During several visits to the Governmental Abattoir, El-Basateen, Cairo a total 400 random slaughtered buffaloes were examined. They were divided as younger less than two years, young 2-5 years and old over 5 years. The carcasses mainly t esophagus, heart, masseter, tongue and diaphragm muscle as well as liver and lungs were carefully inspected. Samples from these organs and blood and fecal samples were collected. Besides, 20 non-coagulated blood samples were collected from slaughtered buffalo calves free from muscle infection and used as negative control.

Small pieces from the muscle samples were compressed between the trichenoscope glass plates for macroscopic and microscopic muscle cysts examination (Webster et al, 2006). Other tissue parasites infection such as Cysticercus bovis, hydatid cyst and Fasciola was taken in consideration.

Sarcocystis bradyzoites antigen (SBAg): This was done after Ali et al. (2016) with little modifications, Sarcocystis bradyzoites were extracted from macroscopic cysts of natural infected buffaloes esophagus (identified as Sarcocystis bovi/hominis) crushed in $0.01 \mathrm{M}$ phosphate buffered saline (PBS) $\mathrm{pH}$ 7.4. After washing, bradyzoites were ruptured in PBS by repeated freezing and thaw- ing (3 times). The contents were sonicated using "Cole parmer ultrasonic Homogenizer "under 150 watt interrupted pulse output at $50 \%$ power cycle in ice bath. Suspension was centrifuged at $10.000 \mathrm{rpm}$ at $4^{\circ} \mathrm{C}$ for 1 hr. Supernatant was collected and its protein content was measured (Lowry et al, 1951) then stored at $-20^{\circ} \mathrm{C}$ until use.

Preparation of specific hyper-immune sera (RHIS): This was done after Tang et al. (2015) with little modification; the prepared SBAg was used to produce hyperimmune sera. Four white New Zealand rabbits were bled for separation of pre immunization negative sera. Two of them were kept as negative control to the study end, while the other two were subcutaneously injected with $1.2 \mathrm{mg}$ protein of SBAg, emulsified 1:1 with mineral oil. After 2 weeks another $1.2 \mathrm{mg}$ protein was mixed 1:1 in the oil and divided into 3 doses (day 14, $21 \& 28$ ) and then subcutaneously injected. One week after the last immunization; the rabbits were bled for serum collection and the level of antibodies was measured. The collected sera were stored at $-20^{\circ} \mathrm{C}$ until used as positive sera.

Fractionation of SBAg \& transferring of protein (Laemmli, 1970): SDS-PAGE analysis of SBAg was carried out under reduced conditions using $12 \%$ non-gradient slab gel with 5\% stacking gel. Antigen was fractionated at a current of $20 \mathrm{~mA}$. The molecular weight markers (Sigma SDS-100B) were used as standard. SBAg fractionated proteins were transferred from the gel at $10 \mathrm{~V}, 100$ $\mathrm{mA}$ overnight at $4^{\circ} \mathrm{C}$, onto nitrocellulose paper (NC). NC sheet was dried and stored at $-20^{\circ} \mathrm{C}$ until use.

Determination of specific protein fractions by EITB: A longitudinal NC strips (12 X 0.4 $\mathrm{cm})$ containing the fractionated SBAg were cut out. After blocking with $0.5 \%$ BSA, the strips were incubated versus known positive and negative control (3 different) serum samples at $1: 100$ dilution, $5.0 \mathrm{ml}$ of sera/strip for $2 \mathrm{hr}$ (Towbin et al, 1979) for Westernblot assay (EITB). After washing, the strips were exposed to 1:1.000 HRP-conjugated 
anti-bovine $\mathrm{IgG}$ (Sigma, USA), at $37^{\circ} \mathrm{C}$ for 1 h. The peroxidase substrate (4-chloro-1naphthol, Sigma) was then added to mark the reacted IgG band fractions. Protein fractions that reacting positively with positive control serum, and in the same time did not react with negative one, were considered as specific fractions (Fig. 1). These strips were retained back to its original position on $\mathrm{NC}$ sheet, the site of the specific protein bands in association with the MW standard were determined.

Extraction of specific protein fractions by Dot-ELISA: After identification of SBAg specific protein fractions as before, new SDS-PAGE analysis was performed. When the gel ran its full length, a longitudinal strips containing the MW standards and the peripheral part of the fractionated antigen, were cut out. The strips were stained with Coomassie blue (Tsai and Frasch, 1982). The sites of the previous specific bands identified via EITB were determined guided by the present MWS in the gel. A transverse gel strips containing the proteins corresponding to MW from 35 to $63 \mathrm{kDa}$ were marked then cut out horizontally across the whole gel. The cut gel strips were transferred to elution tube membrane 6-8 MW cut-off (Spectrum Medical Inc., Los Angeles, CA 900060). The tube was filled with PBS (pH 7.4) and kept in Bio-Rad elution unit at $10 \mathrm{~V}, 100 \mathrm{~mA}$ overnight at $4^{\circ} \mathrm{C}$. After removal to the gel material, eluted $\mathrm{Ag}$ was concentrated using poly-ethylene-glycol in the same previous tubing of 6-8 MW cutoff (Goswami et al, 2013). The protein content of the eluted material was determined as before. Antigen was kept at $-20^{\circ} \mathrm{C}$ till dotted on NC disks for Dot ELISA performing.

Dot-ELISA technique: Technique was done (Swarna et al, 2012) with slight modification. A total of $2.0 \mu \mathrm{l}$ antigen (with 0.2 $\mathrm{mg}$ protein) from the eluted concentrated protein fractions were dotted on NC circular disks kept on micro-ELISA plate bottom. The disks were left to dry at $37^{\circ} \mathrm{C}$ and then blocked by $3 \%$ BSA after 3 time wash with
PBS-T, they left to dry as before. An amount of $2.0 \mu \mathrm{l}$ of sera (in replicates) were spotted on each NC disk and left to dry before adding 50 $\mu \mathrm{l} /$ well from the HRP-conjugated anti-bovine or anti-human (Sigma, USA) at 1:1000 concentration and left for 30 minutes. After washing, 50 $\mu 1 /$ well substrate solution (4-chloro-1- naphthol $34 \mathrm{mg} / \mathrm{ml}$ substrate buffer with $0.03 \%$ hydrogen peroxide solution) was added. The developed color (within $15 \mathrm{~min}$.) was observed by naked eye. Well-defined blue-purple spot was regarded as positive and evaluated in comparison with the reference control in each case each sample was test. Sensitivity was calculated as number of true positive/true positive + false negative. Specificity was calculated as number of true negative/true positive + false negative (Attallah et al, 1997). Test validity was estimated (Sadjjadi et al, 2007) by calcul-ating the mean of sensitivity and specificity (validity $=$ mean sensitivity + mean specificity/2).

Tested buffaloes' sera: Identified blood samples were collected from slaughtered buffaloes. Samples selected for the present study were chosen after fecal examination of each animal on the base that they must have single known infection. These known infected animal sera were used first to standardize the used Dot-ELISA from the aspect of sensitivity and specificity then used to determine the incidence of infection in these animals as a source for infection of the contact workers.

Tested animal sera were 1- Four hundred sample screened for the presence of ASAb, 2- Seventeen sample from animals infected by $C$. bovis, 3-Thirteen samples from animals harbor hydatid cysts in their lung, 4Thirty sample from Fasciola infected buffaloes, \& 5- Twenty sample from animals free from parasitic infection as negative control.

Human samples: After examination of 250 slaughtered house workers complained from some symptoms related to sarcosporediosis such as myositis, arthritis and digestive disturbances, a number of 115 those stool sam- 
ples free from any parasitic infection were selected for this study. This group consists from males of age range from 25 to 50 years old. Identified coagulated and non-coagulated blood and stool samples were collected from each one. The identified sera were separated from the coagulated blood and included in the present study.

The suspected buffaloes' muscle samples were pathological processing, and examination (Pritchard and, Kruse, 1982) results were given (Fig, 2a, b).

A total of 10 sera were collected from Schistosoma mansoni infected patients, 10 sera samples of viral hepatitis C PCR positive patients and 10 sera from healthy individuals were included to evaluate the efficacy of the used Dot ELISA technique.

Fecal and stool examination: Stool and fecal samples were parasitologic examined by using fluke finder technique (Welch et al, 1987) for large size eggs and concentration flotation technique (Solusby, 1982) other eggs, cysts and oocysts. Samples infected by parasites than the target one were excluded.

\section{Results}

In the present study modified Dot ELISA was adopted for diagnosis of ASAb in sera of groups of slaughter house workers complained from some symptoms could be related to infection by sarcospordiosis. These patients considered to be in close contact with meat infected by SMC. In order to figure out the size of the problem around these workers, the first part of the study focused on determination the incidence of infection with different tissue parasites through macroscopic and microscopic examination of the slaughtered carcasses. The data (Tab. 1) revealed a direct relation between increase in the age of slaughtered animals and rate of infection with SMC as it was reached to $62.5 \%$ in animals over 5 years old while it was $8 \%$ and $14 \%$ in animals < 2 years and that of 2-5 years old respectively. With total incidence reached to $36.75 \%$. Infection by C. bovis, Fasciola and hydatid cysts was recorded in $4.25 \%, 7.5 \%$ and $3.25 \%$ in these slaughtered buffaloes respectively.

As sensitivity of ELISA was affected by degree of purity and specificity of the used antigens therefore determination of specific SBAg fraction was done from the tissue cyst extracted from positive animals. The present data (Tab. 1; Fig. 1) showed fractionation of SBAg using SDS-PAGE and identification of specific reacted protein bands versus control positive sera using EITB, revealed 13 protein fractions corresponding to $\mathrm{MW}$ at the level from $15-150 \mathrm{kDa}$. Six fractions corresponding to MW of $30,35,38,48,58$ and $63 \mathrm{kDa}$ reacted specifically versus several treatment by sera from SMC infected animals as well as diluted RHIS. These fractions did not react on similar NC strips treated versus negative control sera (Tab. 2; Fig. 1). Antigens in the gel slid corresponding to the MW of 35 to $63 \mathrm{kDa}$ were eluted, concentrated and used as purified Ag for detection of ASAb in sera of the examined animals and human.

Sera collected from proved positive animals were used to standardize Dot-ELISA test used for sero-diagnosis of these animals. The selected protein fractions used in DotELISA proved absolute sensitivity (100\%) in capture of ASAb in sera of 125 Sarcocystis infected animals as that presented in RHIS at 1:100 \& 1:200 serum dilutions respectively and in the same time it did not prove false positive with control negative sera of buffaloes and rabbits. Besides, the pooled protein fractions proved variable specificity (84.61, $86.66 \& 88.24 \%$ ) on screening the sera collected from animals naturally infected with C. bovis, Fasciola and hydatid cysts respectively, with a validity of $93.33 \%$ (Tab. 3)

Re-screening of the buffaloes sera using Dot-ELISA (Tab. 4) showed ASAb in their sera $(52.5 \%)$ than by macroscopic examination $(36.75 \%)$.

Examination of the sera collected from slaughter house workers after being classified into groups according to their general complains (Tab. 5) showed high association between presence of ASAb in their sera and 
complained from myositis (82.5\%) followed by those suffering from arthritis (76.0\%), and arthritis $(73.33 \%)$. ASAb were recorded in $40 \%$ of patients with digestive disturbances, in $30 \%$ from S. mansoni infected patients and $\mathrm{HCV}$ reacted positively versus $\mathrm{ASAb}$ after sera screening at 1:50 dilution. Increasing the tested serum dilution to 1:100 \& 1:200 succeeded in exclusion of cross reaction with other anti-bodies as at these dilutions no cross reaction was in $S$. mansoni, $\mathrm{HCV}$ infected patients and healthy people and in workers complained from digestive disturbances only. In the same time the recorded $\%$ of the diagnosed ASAb in sera of suspected patients decreased to $50 \%, 44 \%$ \& $66.66 \%$ in those suffered from myositis, arthritis or both respectively after screening of them at 1:100 serum dilutions. The presence of infection did not decreased again after increasing the tested serum dilution to 1:200 (Tab. 5). None parasitic stage was detected in patients' stool of positive Dot-ELISA

Table 1: Incidence of tissue parasites detected in buffaloes (macroscopic \& microscopic examination).

\begin{tabular}{|c|c|c|c|c|c|c|c|c|c|}
\hline & No. & \multicolumn{2}{|c|}{ Sarcocystis cysts } & \multicolumn{2}{c|}{ Cysticercus bovis } & \multicolumn{2}{c|}{ Liver fibrosis } & \multicolumn{2}{c|}{ hydatid cyst } \\
\cline { 3 - 11 } Age group & Examined & Infected & $\%$ & Infected & $\%$ & Infected & $\%$ & Infected & $\%$ \\
\hline <2 years & 100 & 8 & $8.0 \%$ & - & & - & & - & \\
\hline $2-5$ years & 100 & 14 & $14.0 \%$ & 5 & $5.0 \%$ & 8 & $8.0 \%$ & 4 & $4 \%$ \\
\hline$>5$ years & 200 & 125 & $62.5 \%$ & 12 & $6.0 \%$ & 22 & $11.0 \%$ & 9 & $4.5 \%$ \\
\hline Total & 400 & 147 & $36.75 \%$ & 17 & 4.25 & 30 & $7.5 \%$ & 13 & 3.25 \\
\hline
\end{tabular}

Table 2: Specific and non-specific protein fractions of SBAg using Western blot versus positive \& negative sera.

\begin{tabular}{|c|c|c|}
\hline \multirow{2}{*}{$\begin{array}{c}\text { Band } \\
\text { No }\end{array}$} & kDa bands reacted on NC strips with fractionated SBAg treated with sera \\
\cline { 2 - 3 } & Infected buffaloes & Non-infected control buffaloes \\
\hline 1 & $150 \mathrm{kDa}$ & $150 \mathrm{kDa}$ \\
\hline 2 & $135 \mathrm{kDa}$ & $100 \mathrm{kDa}$ \\
\hline 3 & $100 \mathrm{kDa}$ & $70 \mathrm{kDa}$ \\
\hline 4 & $70 \mathrm{kDa}$ & \\
\hline 5 & $-63 \mathrm{kDa} *$ & \\
\hline 6 & $-58 \mathrm{kDa} *$ & \\
\hline 7 & $-38 \mathrm{kDa}{ }^{*}$ & $28 \mathrm{kDa}$ \\
\hline 8 & $>35 \mathrm{kDa} *$ & $15 \mathrm{kDa}$ \\
\hline 9 & $-30 \mathrm{kDa}$ & \\
\hline 10 & $28 \mathrm{kDa}$ & \\
\hline 11 & $18 \mathrm{kDa}$ & \\
\hline 12 & $15 \mathrm{kDa}$ & \\
\hline 13 & \multicolumn{3}{|c|}{ Specific fractions, $*$ area of bands selected for dot ELISA. } \\
\hline
\end{tabular}

Table 3: Sensitivity \& specificity of Dot ELISA in diagnosis of ASAb in sera (Validity 93.33\%)

\begin{tabular}{|c|l|c|c|c|}
\hline & \multicolumn{1}{|c|}{ History of tested sera } & No. Ex. & No. +ve & $\%$ \\
\hline \multirow{4}{*}{ Sensitivity } & Buffaloes harbors SCMC & 125 & 125 & 100 \\
\cline { 2 - 5 } & RHIS (reference +Ve) (1:200) & 2 & 0.0 & 100 \\
\cline { 2 - 5 } & Control non-infected buffaloes & 20 & 0.0 & 100 \\
\cline { 2 - 5 } & Control non-injected rabbits & 2 & 0.0 & 100 \\
\hline \multirow{3}{*}{ Specificity } & Buffaloes harbors Cysticercus bovis & 17 & 2 & 88.24 \\
\cline { 2 - 5 } & Buffaloes with fibrosed liver & 30 & 4 & 86.66 \\
\cline { 2 - 5 } & Buffaloes infected with Hydatid cyst & 13 & 2 & 84.61 \\
\hline
\end{tabular}

Table 4: Screening of inspected buffalo cases for ASAb using Dot ELISA

\begin{tabular}{|l|c|c|}
\hline \multicolumn{1}{|c|}{ Tested animals } & Number $+\mathrm{v}$ e & Positive $\%$ \\
\hline Strong $+\mathrm{Ve}$ & 172 & 43 \\
\hline Weak $+\mathrm{Ve}$ & 38 & 9.5 \\
\hline Total $+\mathrm{Ve}$ & 210 & 52.5 \\
\hline Negative & 190 & 47.5 \\
\hline
\end{tabular}


Table 5: Incidence of ASAb in the examined workers and control using Dot- ELISA

\begin{tabular}{|l|c|c|c|c|c|c|c|}
\hline \multirow{2}{*}{ Patients complains } & \multirow{2}{*}{$\begin{array}{c}\text { No. } \\
\text { Examined }\end{array}$} & \multicolumn{2}{|c|}{$1: 50$} & \multicolumn{2}{c|}{$1: 100$} & \multicolumn{2}{c|}{$1: 200$} \\
\cline { 3 - 8 } & No. +ve & $\%$ & No. +ve & $\%$ & No. +ve & $\%$ \\
\hline Myositis & 40 & 33 & 82.5 & 20 & 50.0 & 20 & 50.0 \\
\hline Arthritis & 25 & 19 & 76.0 & 11 & 44.0 & 11 & 44.0 \\
\hline Myositis \& Arthritis & 30 & 22 & 73.33 & 20 & 66.66 & 20 & 66.66 \\
\hline Digestive disturbances & 20 & 8 & $40.0 \%$ & 0 & -- & 0 & -- \\
\hline Schistosomiasis & 10 & 3 & $30.0 \%$ & 0 & -- & 0 & -- \\
\hline Hepatitis patients & 10 & 3 & $30.0 \%$ & 0 & -- & 0 & -- \\
\hline RHIS (reference +ve) & 2 & 2 & $100 \%$ & 2 & $100 \%$ & 2 & $100 \%$ \\
\hline Healthy control & 10 & 0.0 & 0.0 & 0.0 & 0.0 & 0.0 & 0.0 \\
\hline
\end{tabular}

\section{Discussion}

Sarcosporidiosis is one of the neglected zoonotic diseases. Human can act as the final host (shed mature Sarcocystis oocyst in stool) or as IMH (harboring the SMC in their muscles) for some Sarcocystis species. Human infection cause large number of nonspecific symptoms that can interfere with many infections such as myilgia, arthritis (Cook and Zumla, 2003). No pre-slaughter test was applied for inspection of this parasite in muscles of living animals.

Primary inspection of the slaughtered buffaloes using macroscopic and microscopic methods showed that the total incidence of infection reached to $36.75 \%$. This was lower than that mentioned by Sabry and Shalaby (2004) in the same locality but agreed with the fact that the infection was high in old aged buffaloes than younger one. Also, the present study showed a direct relation between increase in the age of slaughtered animals and SMC infection rate. It was $62.5 \%$ in animals over 5 years old and $8 \%$ \& $14 \%$ in animals $<2$ years and that of $2-5$ years respectively. This result agreed with Ahmed et al. (2016) who recorded higher infection rate in old aged buffaloes in the Governormental El-Kharga Abattoir.

Nowadays, serological tests proved to be more beneficial for diagnosis of parasitosis, but their sensitivity might be affected by the degree of purity and specificity of the used sera and antigens to avoid the cross-reaction (Taher, 2012). For this reason identification of special antigenic fraction improved the accuracy of the used diagnostic technique (Irabuena et al, 2000). EITB is one of the most specific sero-diagnostic techniques but not so specific in field application as ELISA (Ibarra et al, 1998). Dotting of very small amounts of EITB specific eluted concentrated protein fractions as antigen onto $\mathrm{NC}$ membranes (modified dot ELISA), considered enough to obtain a marked accurate diagnosis for the parasite directly. This test was reported by El-Bahy (2002) and AbdelMawgood et al. (2015) as being rapid, economic, suitable for small quantities of purified antigens and easily evaluated visually.

In the present study, fractionation of SBAg revealed 13 protein fractions have MW ranged from 15- $150 \mathrm{kDa}$. Six fractions corresponding to MW of $30,35,38,48,58$ \& $63 \mathrm{kDa}$ reacted specifically versus several treatment by sera from SMC infected animals and diluted RHIS. These data agreed with Abdel-Maogood et al. (2015) $\mathrm{m}$ but disagreed with Mamatha et al. (2008). Specific fractions corresponding to the MW of 35- $63 \mathrm{kDa}$ were eluted and concentrated then used as purified $\mathrm{Ag}$ for detection of ASAb in sera of examined animals and humans by Dot ELISA.

In the present study, detection of ASAb in the sera of the previous examined buffaloes versus the purified $35-63 \mathrm{kDa}$ protein fractions in Dot-ELISA revealed an increase in the rate of infection in these animals to $52.5 \%$. This increase agreed with Sabry and Reda (2008) who reported that antibodies detection was more accurate than the microscopic examination. The used Dot-ELISA proved absolute sensitivity $(100 \%)$ on the screening of animals already diagnosed as harboring sarcosporidiosis in their muscle. 
Concerning specificity of this test $2,4 \& 2$ animals naturally infected with $C$. bovis, Fasciola and hydatid cysts respectively reacted positively versus SBAg, which might be related to the presence of true infection in these animals rather than as cross reaction.

After standardization of Dot-ELISA using known infected buffaloes' sera and RHIS, the test was used to inspect the complained slaughter house workers. The data revealed high association between the presence of ASAb in sera of patients complained from Myositis $(82.5 \%)$ followed by those suffering from Arthritis (76.0\%) then by those affected by Myositis and arthritis (73.33\%). ASAb was recorded also in $40 \%$ in the patients complained from the digestive disturbances. Moreover, $30 \%$ from the $S$. mansoni infected patients and HCV reacted positively versus $\mathrm{ASAb}$ at 1:50 serum dilution. These values decreased to $50 \%, 44 \%$ and $66.66 \%$ in those complained from myositis, arthritis or both respectively after screening of them at 1:100 \&1:200 serum dilutions with exclusion to cross reaction with other affections.

In the present study, cross reaction was recorded between ASAb and both $S$. mansoni and HCV infected patients at 1:50 dilution, which agreed with Khalil et al. (1990). Increasing the serum dilution to $1: 100$ or 1:200 excluded the cross reaction. This agreed with Ibarra et al. (1998) who by ELISA did not find cross reactions between Sarcocystis and Toxoplasma by increasing the serum dilution. Dot-ELISA proved to be a dependable sero-diagnostic test (Sadjjadi et al, 2007 ) with a validity of $93.33 \%$.

The present study considered using of the Dot-ELISA that depended on EITB purified specific Ag as a sensitive specific technique. Using this technique on pre-slaughtered animals identified infected ones. This way led to slaughter animals under restricted control measures including the required control system and condemnation of infected part to stop infective stages to other animals, birds and the zoonosis transmission as well (Sabry and Reda, 2008).
Increasing the infection rate especially in the carcasses of the condemned parts as esophagus which was considered to be as one of the predilection sites in animals, spread to the workers, as well as to dogs and cat usually found in the slaughter houses and in the surrounding areas (Morsy et al, 2011). Most sarcocysts in humans were found in skeletal muscle and cardiac muscle, but sarcocysts have also been found in muscles in the lary$\mathrm{nx}$, pharynx, and upper esophagus (Lele et $a l, 1986)$. To prevent infection of food animals, they must be prevented from ingesting the sporocyst stage from human feces in the contaminated water, feed, and bedding.

When such preventative measures cannot be assured and the meat might be harboring cysts, it should be thoroughly frozen for 2 days or more or thoroughly cooked to kill the infective bradyzoites (Fayer, 2004).

\section{Conclusion}

No doubt, Sarcocystis is an emerging zoonotic problem with high infection incidence in man and animals. So, special attention must be focused to increase the knowledge of those workers about how they can protect themselves from direct or indirect exposure to this parasite as well as application of strict control measures in slaughter houses to prevent infection of stray dogs and cats, which minimize spread of this disease around the contact human.

The importance of applying the strict control measures in slaughter houses and proper meat inspection procedures to prevent arrival of the condemned muscles to stray dogs and cats, the matter which minimize spread of these diseases around the contact human.

\section{References}

Abdel-Maogood, SZ, Abdel-Wahab, AM, Mahrous, LN, 2015: Improved Dot ELISA technique for diagnosis of some tissue parasites infecting donkeys. Int. J. Chem Tech Res., 8, 12: 94-103.

Ahmed, AM, Elsharawy, NT, Youssef, AI, 2016: Survey on Sarcocystis in bovine carcasses slaughtered at the municipal abattoir of El-Kharga, Egypt. Vet. World 9, 12:1461-5. 
Ali, AI, Hatthot, AH, Latif, FA, 2016: Molecular identification of microscopic Cysts of Sarcocystis in sheep in Baghdad Province. Int. J. Adv. Res. Biol. Sci. 3, 11:200-5.

Arness, MK, Brown, JD, Dubey, JP, Neafie, R C, Granstrom, DE, 1999: An outbreak of acute eosinophilic myositis attributed to human Sarcocystis parasitism. Am. J. Trop. Med. Hyg. 61, 4:548-53.

Ashmawy, KI, Abu-Akkada, SS, Ghashir, MB, 2014: Prevalence and molecular characterization of Sarcocystis species in water buffaloes (Bubalus bubalus) in Egypt. Trop Anim. Hlth Prod. 46, 8:1351-6.

Attallah, AM, El-Masry, SA, Rizk, H, Ismail, H, El-Bendary, M, et al, 1997: Fast-Dot ELISA using urine, a rapid and dependable field assay for diagnosis of schistosomiasis. J. Egypt. Soc. Parasitol. 27, 1:279-89.

Badawy, AI, Abouzaid, NZ, Ahmed, H, 2012: Sarcocystis hominis and other Sarcocystis species infecting cattle in Sharkia Province, Egypt. J. Am. Sci. 8, 8:271-5.

Bunyaratvej, S, Unpunyo, P, Pongtippan, A, 2007: The Sarcocystis-cyst containing beef and pork as the sources of natural intestinal sarcocystosis in Thai people. J. Med. Assoc. Thail. 90: 2128-35.

Cocuz, ME, 2014: Diagnostic difficulties in human trichinellosis: A case report. Bulletin of the Transylvania University of Braşov Series VI: Med. Sci. 7, 56:2-4.

Cook, GC, Zumla, AI, 2003: Manson's Tropical Diseases.(2 $2^{\text {nd }}$ edition) Elsevier Science Ltd, Robert Stevenson House,1-3 Baxter's place, Leith Walk, Edinburgh EH1 3AF.

Dubey, JP, Fayer, R, 1983: Sarcocystosis. Br. Vet. J. 139:371-7.

El-Bahy, NM, 2002: Diagnosis of Fasciola infection by Dot ELISA technique using SDSPAGE eluted excretory secretary (ES) protein fractions. $2^{\text {nd }}$ Vet. Cong. Fac. Vet. Med. Sadat City, Menoufia, Egypt.

El-Morsey, A, El-Seify, M, Desouky, AR, Abdel-Aziz, MM, Sakai, H, et al, 2014: Morphologic identification of a new Sarcocystis sp. in the common moorhen (Gallinula chloropus ) (Aves: Gruiformes: Rallidae) from Brolos Lake, Egypt. Parasitol. Res. 113, 1:391-7.

Fayer, R, 2004: Sarcocystis spp. in human infections. Clin. Microbiol. Rev. 17, 4:894-902.

Fayer, R, Esposito, DH, Dubeya, JP, 2015: Human infections with Sarcocystis species. Clin.
Microbiol. 28, 2:295-311.

Goswami, A, Das, D, Laha, R, 2013: Characterization of immunogenic proteins of Cysticercus tenuicollis of goats. Vet. World 6, 5:267-70.

Hewitson, JP, Grainger JR, Maizels, RM, 2009: The role of parasite secreted proteins in modulating host immunity. Mol. Biochem. Parasitol. 167, 1:1-11.

Ibarra, F, Montenegro, N, Vera, Y, Boulard, C, Flores, J, et al, 1998: Comparison of three ELISA tests for seroepidemiology of bovine fascioliasis. Vet. Parasitol. 77:229-36.

Irabuena, O, Nieto, A, Ferreira, AM, Battistoni, J, Ferragut, G, 2000: Characterization and optimization of bovine Echinococcus granulosus cyst fluid to be used in immunodiagnosis of hydatid disease by ELISA. Rev. Inst. Med. Trop. Sao. Paulo 42, 5:255-62.

Khalil, HM, Abdel-Aal TM, Makhled, MK, Abdallah, HM, Fahmy, IA, et al, 1990: Specificity of crude and purified Fasciola antigens in immunodiagnosis of human fascioliasis. J. Egypt. Soc. Parasitol. 20, 1:87-94.

Laemmli, UK, 1970: Cleavage of structural proteins during the assembly of the head of Bacteriophage $T$ 4. Nature 227:680-5.

Langley, RJ, Hillyer, GV, 1989: Detection of circulating parasite antigen in murine fascioliasis by two-site enzyme-linked immunosorbent assays. Am. J. Trop. Med. Hyg. 41:472-8.

Lele, VR, Dhopavkar, PV, Kher. A. 1986: Sarcocystis infection in man. Indian J. Pathol. Microbiol. 29:87-90.

Lowry, OH, Rosenbrough, NJ, Farr, AL, Randall, R. (1951): Protein measurement with the phenol reagent. J. Biol. Chemist. 193:265-75.

Lunde, MN, Fayer, R, 1977: Serological test for antibody to Sarcocystis in cattle. J. Parasitol. 63, 2: 222-5.

Mamatha, GS, D'Souza Placid, E, Suryaarayana, VVS, 2008: Serodiagnosis of bovine sarcocystosis by enzyme immuno transfer blot (EITB) in naturally infected cattle. J. Vet. Parasitol. 22: 269-72.

Morsy, K, Saleh, A, Al-Ghamdi, A, AbdelGhaffar, F, Al-Rasheid, K, et al, 2011: Prevalence pattern and biology of Sarcocystis capracanis infection in the Egyptian goats: a light and ultrastructural study. Vet. Parasitol. 181, 2/4:7582.

Prestwood, AK, Cahoon, RW, McDaniel, HT, 1980: Sarcocystis infections in Georgia swine. Am. J. Vet. Res. 41, 1:876-81. 
Pritchard, MN, Kruse, CO, 1982: The Collection and Preservation of Animal Parasites. Library of Congress Cataloguing in Publications.

Rommel, M, 1989: Recent advances in the knowledge of the biology of the cyst-forming coocidia. Angew Parasitol. 30, 3:173-83.

Sabry, MA, Reda, WW, 2008: Infection by cyst-producing protozoa among human \& food producing animals in Egypt. J. Biol. Sci. 8, 1:1-7.

Sabry, MA, Shalaby, HA, 2004: Sarcosporidiosis as an emerging zoonotic disease. J. Vet. Med. Mounifia Univ. 1:112-9.

Sadjjadi, SM, Abid, H, Sarkani, B, Izadpanah, A, Kazemina, S, 2007: Evaluation of ELISA, utilizing native antigen $B$ for serodiagnosis of human hydatidosis. Iran. J. Immunol. 4, 3:167-9. Saeed, MA, Rashid, MH, Vaughan, J, Jabbar, A, 2018: Sarcocystosis in South American camelids: The state of play revisited. Parasit Vectors Mar 6;11(1):146. doi: 10.1186/s13071-0182748-1.

Shaapan, RM, 2016: The common zoonotic protozoal diseases causing abortion. J. Parasit. Dis. 40, 4:1116-29.

Soulsby, EJ, 1982: Helminthes, Arthropods and Protozoa of Domesticated Animals (Textbook). $6^{\text {th }}$ Edition. Bailliere Tindall \& Cassell; London. Swarna, SR, Parija, SC, 2012: Evaluation of
Dot-ELISA and enzyme-linked immuno-electrotransfer blot assays for detection of a urinary hydatid antigen in the diagnosis of cystic echinococcosis. Trop. Parasitol. 2:38- 44.

Taher, ES, 2012: Does the origin of hydatid cyst antigen affect diagnosis of human hydatidosis? J. Appl. Sci. Res. 8, 4:1952-8.

Tang, B, Liu, M, Wang, L, 2015: Characterization of a high-frequency gene encoding a strongly antigenic cystatin-like protein from Trichinella spiralis at its early invasion stage. Parasites Vectors 8:78-80.

Towbin, H, Stachelin, T, Gordon, J, 1979: Electrophoretic transfer of proteins from polyacrylamide gels to nitrocellulose sheets: Procedures and some applications. Proc. Nat. Acad. Sci. USA, 76:4350-4.

Tsai, CM, Frasch, CE, 1982: A sensitive silver stain for detecting lipopolysaccharides in polyacrylamide gels. Anal. Biochemis. 119:115-9.

Webster, P, Maddox-Hyttel, C, Nöckler, K, Malakauskas, A, et al, 2006: Meat inspection for Trichinella in pork, horsemeat and game within the EU: available technology and its present implementation. Euro Surveill. 11, 1:596-9. Welch, S, Malone, J, Geaghan, H, 1987: Herd evaluation of Fasciola hepatica infection in Louisiana cattle by an ELISA. Am. J. Vet. Res. 48:345-7.

\section{Explanation of figures}

Fig. 1: Recognition of fractionated SBAg on NC strips versus control positive and negative buffaloes sera using EITB technique. MW St: Low Molecular weight protein slandered (Sigma), Lane 1: Fractionated SBAg on NC strip treated by infected buffalo sera, Lane 2: Fractionated SBAg on NC strip treated by non-infected buffalo sera, (-) means SBAg specific protein fractions.

Fig. 2: a- Macroscopic S.C. M. cyst in oesophagial muscle of saughtered infected buffalo, and b-Micro-cyst diagnosed in stained section of suspected muscle
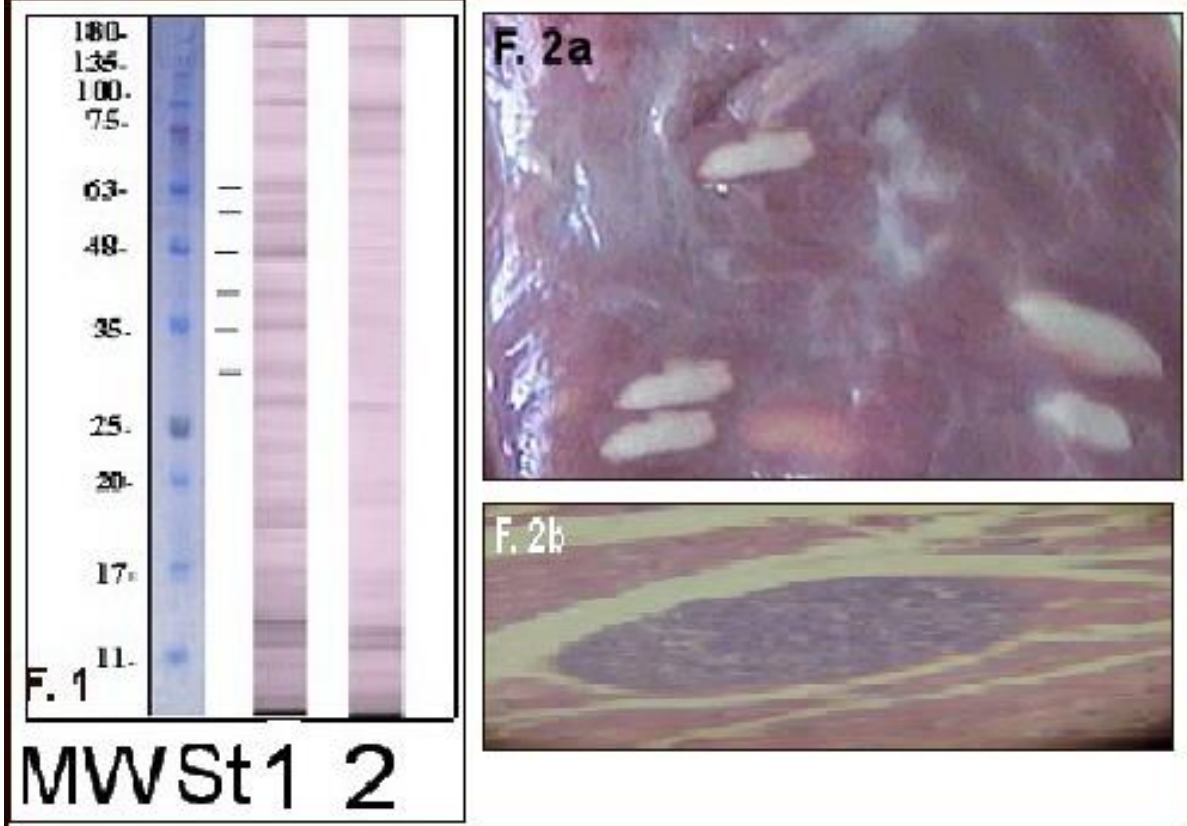